\title{
PROPERTIES OF DEBRIS-LADEN ICE:
}

\section{APPLICATION TO THE FLOW RESPONSE OF THE GLACIERS ON MOUNT ST HELENS}

\author{
(Abstract only)
}

\author{
by \\ Melinda M. Brugman \\ (Division of Geological and Planetary Sciences, California Institute of Technology, Pasadena, \\ California 91125, U.S.A.)
}

\section{ABSTRACT}

Intense deformation within an extensive englacial debris layer appears to be a dominant flow mechanism for glaciers on Mount St Helens, Washington.

observations of this phenomenon have been made on Shoestring Glacier and more recently on other glaciers on the volcano. Transverse velocity profiles on Shoestring Glacier have shown a marked plug flow behavior occurring between narrow marginal zones of crevassing. Both longitudinal and transverse velocity profiles on Shoestring Glacier were measured during the year before and the two years after the cataclysmic eruption of the volcano on 18 May 1980.

The geometry and regime of every glacier on Mount St Helens dramatically changed during the eruption. The entire accumulation area of Shoestring Glacier was removed by a volcanic landslide and blast, and the glacier surface was deeply incised through the action of pyroclastic flows and mudflows. Surface velocity measurements were supplemented by vertical profiles taken along the newly exposed ice cliffs. Large velocity gradients seen in the transverse, longitudinal and vertical profiles coincided with the mapped location of a recently exposed englacial debris layer. Further detailed measurements on the vertical profiles show that the intense shear occurs by deformation internal to the debris layer. A study of the properties of debris-laden ice was undertaken to determine the mechanism for localization of deformation to the debris layer and for the associated response of the glacier to a sudden change in stress.

For more details see:

Brugman M, Meier M 1982 Response of glaciers to the eruptions of Mount St Helens. US Geological Survey Professional Paper 1250: 743

\section{MODELLING TECHNIQUES IN APPLIED GLACIOLOGY:}

\section{NUMERICAL MODELLING OF AVALANCHES}

\section{(Abstract only)}

\section{G. Brugnot}

(Division Nivologie, Centre National du Machinisme Agricole du Génie Rural des Eaux et des Fôrets, Domaine Universitaire, B.P. 114, 38402 St-Martin-d'Hères, France)

\section{ABSTRACT}

We consider the paper by Brugnot and Pochat (1981), which describes a one-dimensional model applied to a snow avalanche. The main advance made here is the introduction of the second dimension in the runout zone. Indeed, in the channelled course, we still use the one-dimensional model, but, when the avalanche spreads before stopping, we apply a $(x, y)$ grid on the ground and six equations have to be solved: (1) for the avalanche body, one equation for continuity and two equations for momentum conservation, and (2) at the front, one equation for continuity and two equations for momentum conservation. We suppose the front to be a mobile jump, with longitudinal velocity varying more rapidly than transverse velocity.
We solve these equations by a finite difference method. This involves many topological problems, due to the actual position of the front, which is defined by $i$ ts intersection with the reference grid $\left(S_{I}, Y_{J}\right)$. In the near future our two directions of research will be testing the code on actual avalanches and improving it by trying to make it cheaper without impairing its accuracy.

\section{REFERENCE}

Brugnot G, Pochat R 1981 Numerical simulation study of avalanches. Joumal of Glaciology 27(95): $77-88$ 